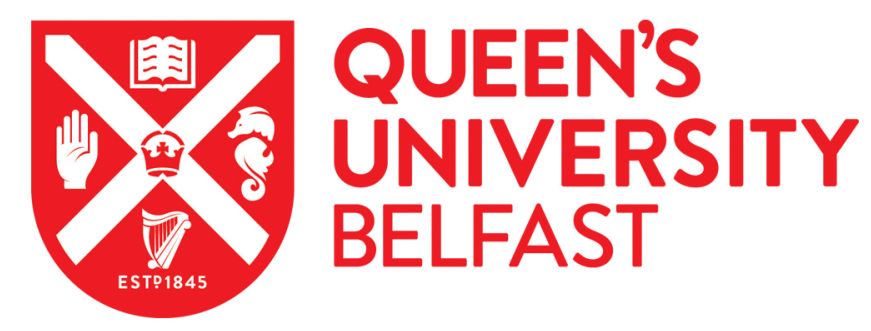

\title{
Becoming part of a temporary protest organization through embodied walking ethnography
}

Lubit, A. J., \& Gidley, D. (2020). Becoming part of a temporary protest organization through embodied walking ethnography. Journal of Organizational Ethnography, 10(1), 79-94. https://doi.org/10.1108/JOE-08-2020-0033

Published in:

Journal of Organizational Ethnography

Document Version:

Peer reviewed version

Queen's University Belfast - Research Portal:

Link to publication record in Queen's University Belfast Research Portal

\section{Publisher rights}

Copyright 2020 Emerald.

This manuscript is distributed under a Creative Commons Attribution-NonCommercial License (https://creativecommons.org/licenses/by$\mathrm{nc} / 4.0 /)$, which permits distribution and reproduction for non-commercial purposes, provided the author and source are cited.

\section{General rights}

Copyright for the publications made accessible via the Queen's University Belfast Research Portal is retained by the author(s) and / or other copyright owners and it is a condition of accessing these publications that users recognise and abide by the legal requirements associated with these rights.

Take down policy

The Research Portal is Queen's institutional repository that provides access to Queen's research output. Every effort has been made to ensure that content in the Research Portal does not infringe any person's rights, or applicable UK laws. If you discover content in the Research Portal that you believe breaches copyright or violates any law, please contact openaccess@qub.ac.uk. 
Accepted copy for institutional repository

\section{Citation}

Lubit, A.J. and Gidley, D. (2020), "Becoming part of a temporary protest organization through embodied walking ethnography", Journal of Organizational Ethnography, Vol. ahead-of-print No. ahead-of-print. https://doi.org/10.1108/JOE-08-2020-0033

Accepted September 1st, 2020

Published December 15th, 2020

https://www.emerald.com/insight/content/doi/10.1108/JOE-08-2020-0033/full/html

Deposit licences

Emerald allows authors to deposit their AAM under the Creative Commons Attribution Non-commercial International Licence 4.0 (CC BY-NC 4.0). To do this, the deposit must clearly state that the AAM is deposited under this licence and that any reuse is allowed in accordance with the terms outlined by the licence. To reuse the AAM for commercial purposes, permission should be sought by contacting permissions@emeraldinsight.com.

For the sake of clarity, commercial usage would be considered as, but not limited to:

o Copying or downloading AAMs for further distribution for a fee;

o Any use of the AAM in conjunction with advertising;

o Any use of the AAM by for promotional purposes by for-profit organisations;

- Any use that would confer monetary reward, commercial gain or commercial exploitation. 
Becoming Part of a Temporary Protest Organization through Embodied Walking Ethnography

\begin{abstract}
Purpose - This paper explores the consequences of researching temporary protest organizations through embodied ethnography, paying attention to how, when and why a researcher takes sides.
\end{abstract}

Methodology - The authors employed embodied walking ethnography to study Lyra's Walk, a three-day, 68-mile protest walk held in May 2019 to advocate for peace in Northern Ireland. Data was primarily ethnographic, complemented by an analysis of social media, photos, video, and media coverage.

Findings - First we argue that embodied walking ethnography can provide an inhabited understanding of organizing. The social, physical and emotional experiences of walking encourage researchers to identify more closely with participants and obtain a greater understanding of the phenomena studied. Second, we identify that methodological choice can have a greater impact on side-taking than either the conflict setting or organization researched.

Research implications - This paper demonstrates the promise and consequences of using embodied walking ethnography to study a mobile organization. It further illustrates the nuances and challenges of conducting ethnography in a temporary protest organization.

Originality/value - The paper makes two contributions. The novel use of embodied walking ethnography to study temporary protest organizations can lead the research to become intertwined with the temporary organization during its process of organizational becoming. 
With the researcher's body acting as a research tool, their sensations and emotions impact data collection, interpretation, and findings.

Keywords - social movement, embodiment, walking ethnography, temporary organizations, conflict, Northern Ireland 


\section{Introduction}

Conflict and post-conflict studies in Northern Ireland tend to focus on the two parties to the sectarian conflict - Protestants/Unionists and Catholics/Nationalists - with less attention on third-party perspectives that prioritise peace and reconciliation. From an organizational perspective, research in Northern Ireland commonly focuses on permanent organizations or institutions such as the police (Murphy, 2015), or on recurring formal sectarian rituals such as annual parades (Bryan, 2017). As a non-sectarian temporary organization, Lyra's Walk for Peace represented an unusual situation that deserved further exploration to better understand the complexity of Northern Ireland organizations and institutions. Additionally, it presented an opportunity to demonstrate the value in examining alternative methodologies for researching protest and temporary organizations, beyond participant observation and interview. We identified that our choice of methodology affected our perspective on the organization, indicating that researchers must consider the ways in which they take sides through their research.

In May 2019, both researchers participated in Lyra's Walk for Peace (hereafter referred to as Lyra's Walk), walking across the province of Northern Ireland over three days as part of a temporary protest organization. We identified two ways in which our research methodology required us to take sides. First, by choosing to research this organization through embodied walking ethnography, a participatory method of research, we explicitly joined the protest in body to become part of the temporary organization. Second, by acting simultaneously as participants and researchers, we continuously negotiated our roles within the organization, remaining self-aware of when and how we took sides throughout the event. Both the protest setting and the temporary nature of the organization pushed us to identify more closely with fellow participants; yet our methodological choice to engage in an embodied and mobile form 
of research contributed most to our taking sides with other participants and the organization of Lyra's Walk.

This paper draws on literature relating to temporary organizations and embodied and walking methodologies. We seek to answer the following research question: how does the use of embodied walking ethnography impact the study of protest organizations? With this question in mind, we have identified two contributions to the literature. First, due to the bodily sensations and emotions researchers experience when using embodied walking ethnography, the researcher cannot remain impartial but by necessity identifies with other participants sharing in the same physical and emotional journey. Second, we demonstrate how the use of this methodology in an informal project-like temporary organization leads the research to become intertwined with the organization during its process of organizational becoming. This forces the researcher to identify more closely with the organization and provides for deeper insights into organizational complexity from start to end.

The article is structured in the following way. First, we provide an organizational context, discussing the conflict in Northern Ireland and details of Lyra's Walk. Second, we review the literature on protests as temporary organizations and on walking and embodied methodologies. Third, we detail our data collection and data analysis approaches. Fourth, we provide ethnographic accounts of Lyra's Walk, discussing the process of becoming a part of the organization. Finally, we end with concluding remarks about taking sides in this type of temporary protest organization. 


\section{Organizational Context}

\section{The History of Conflict in Northern Ireland}

The island of Ireland has a long and complex history of sectarian conflict. In response to the Irish War for independence, in 1922 the British government partitioned the island on the basis of community identity, creating the Catholic-dominated Irish Free State as a new nation and Protestant-dominated Northern Ireland as a province within the United Kingdom. Following partition, tensions grew between the Protestant majority and Catholic minority leading to the development of paramilitary groups. The Catholic civil rights movement of 1967 sparked armed conflict between the British government and paramilitaries resulting in "The Troubles," a period of violent sectarian conflict that entrenched divisions between communities from 1969 to 1998 (Bryan, 2017). In simplified terms, while Protestants/Unionists want Northern Ireland to remain a part of the United Kingdom, Catholics/Nationalists want to reunify with the Republic of Ireland.

After 30 years of violent conflict, the 1998 Good Friday Agreement (GFA) facilitated peace, but it also created rigid structures that institutionalized and prioritized the two sides of the sectarian conflict (Graham \& Nash, 2006). Despite the peace process, paramilitary groups and political divisions remain, with violence occasionally erupting. (Balcells et al., 2016; Bryan, 2017). Sectarian divisions have real impacts upon everyone living in Northern Ireland, structuring daily experiences in terms of where and when people feel safe, where they spend their time, and how they engage with people and spaces around them (Jarman \& Bell, 2012). These divisions are visible in the ongoing contestation of public spaces in Northern Ireland with widespread residential, social and educational segregation. Tensions regularly spark between the two dominant communities with public spaces marked by symbols of sectarian identity like flags, banners, murals, graffiti, and public parades (Balcells et al., 2016; Bryan 
2017). These symbols and activities make territorial segregation highly visible and maintain perceptions of difference and hostility between the two communities.

Sectarianism has also structured the region's politics and government since peace was established. The GFA served as both a peace agreement and a framework for the government of Northern Ireland, establishing an Executive based on power-sharing between Unionist and Nationalist political parties. This arrangement structures politics and inter-community relationships today and has proved problematic (Graham \& Nash, 2006). Polarization has only escalated, leading to the eventual collapse of the Executive in January 2017; with the two power-sharing parties unwilling to cooperate, Northern Ireland's government did not reform until January 2020, creating a great deal of public uncertainty and frustration (The Guardian, 2020).

As researchers in Northern Ireland, we are at risk of taking sides merely by researching certain people, organizations and spaces. Becker (1967) argues that since researchers can never fully separate their personal and political biases from their research, they must remain conscious of the sides that they do take. He defines taking sides as "when the research gives credence, in any serious way, to the perspective of the subordinate group in some hierarchical relationship" (ibid., pp. 240). Through the act of participating in Lyra's Walk, both researchers declared themselves to be taking the side of protesters regardless of their personal beliefs.

\section{Lyra's Walk for Peace}

On April 18, 2019 the 29-year-old journalist Lyra McKee was shot and killed by a member of a dissident paramilitary group while reporting on a police raid-turned-riot in the heavily sectarian neighborhood of Derry/Londonderry (O’Neill, 2019). Lyra's death was heavily 
politicized from the start, sparking public outrage at ongoing social divisions, the collapsed government and paramilitary violence in Northern Ireland. To honor her memory and advocate for an end to sectarian polarization, Lyra's friends developed and organized Lyra's Walk in May 2019, just one month after her death. Their charter declared "Lyra's death reminded all of us of the loss, suffering and tragedy of our shared past...By walking for Lyra we protest against the use of violence and the return of killing to our streets" (@lyraswalk, 2019b).

Figure 1. Map of Lyra's Walk route, from Writer's Square in Belfast to Guildhall in Derry. Adapted from Google Maps.

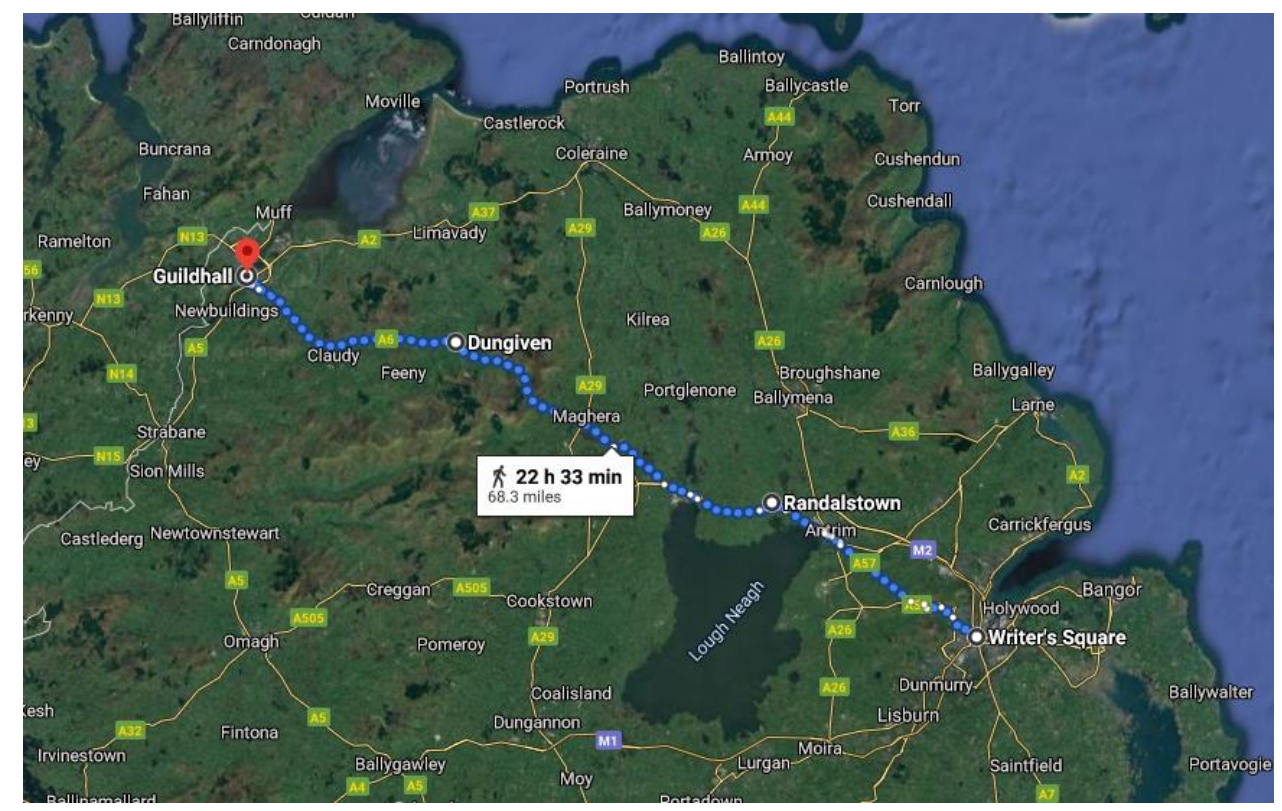

Lyra's Walk was conceived as a 3-day walk (Saturday through Monday) that would travel approximately 20 miles each day for a total of 68-miles, from Belfast to Derry/Londonderry (see Figure 1). Using Eventbrite, the organizers encouraged members of the public to sign up to participate in various ways, to provide support or to walk "one mile or the lot" (@lyraswalk, 2019a). Non-walking forms of participation included donations of funds or supplies; volunteering to drive cars alongside walkers to carry belongings and provide the 
opportunity for breaks; driving a truck carrying camping supplies for those participants camping overnight; stewards walking alongside protestors to help manage the group; police facilitating traffic control and safety; and the provision of rest stops with bathroom facilities, food and drinks.

Approximately 300 individuals participated by walking, including a few children and dogs, but not everyone walked the entire way, making it difficult to get an accurate count of participants at any given stage. The core group of walkers consisted of around 70 people who walked all three days and camped overnights at rest stops. Most walkers only participated in part of the walk. Approximately 30 individuals were present in Belfast at the start of the walk then left at the first rest stop, after completing the first few miles. Another 100 to 150 people, the largest group of participants, joined throughout day three to complete the final day and walk into Derry. Other participants were more difficult to count as they came and went at different places and times. Some walked only a few miles on a chosen day, others returned to participate as much as they were able on several days, and some walked the entirety but returned home to sleep in their own beds rather than camp overnight and then re-joined the walk in the morning.

The organizers did not stake a claim to either side in the sectarian conflict, but rather "enlarged the scope of the political conflict to include a party not ordinarily brought in" (Becker, 1967, pp. 245). They positioned themselves as a third-party alternative to the twoparty conflict between Protestant/Unionist and Catholic/Nationalist, defining themselves by their desire for an end to violence and conflict. Although taking sides in Northern Ireland often refers to siding with one of the two communities, our research instead focused on this third-party that seeks to build relationships across sectarian lines. Lyra's Walk represented a subordinate party to the conflict, seeking to change power relations so that a third non- 
sectarian voice could propose an alternative to sectarianism. While a sizable body of research exists into the conflict in Northern Ireland, this third-party perspective on the conflict has received little attention in the literature.

We conceptualize Lyra's Walk as an informal project-like temporary organization. Bakker (2010, pp. 468) defines temporary organizations as "a set of organizational actors working together on a complex task over a limited period of time." In the case of Lyra's Walk, we identify an emphasis on action (Lundin \& Soderholm, 1995) and "intentional temporariness" (Sydow \& Windeler, 2020, pp. 10) as two important features of the organization. The organizers and participants shared similarities with what Jacobsson \& Hällgren (2016) call “impromptu teams" - self-selecting members who come together in response to an unexpected event. In these situations, organizing occurs from the bottom-up and is best described as informal. Additionally, in what Packendorff and Lindgren (2013) refer to as the broad view of projects, Lyra's Walk consists of "project-like circumstances" that may not be explicitly talked about as a project. Based on this, we will next discuss relevant literature on temporary organizations.

\section{Protest as a Temporary Organization}

Two pertinent developments in the study of temporary organizations include an emphasis on context and expanded empirical settings (for recent reviews, see Bakker, 2010; Burke \& Morley, 2016; Sydow \& Windeler, 2020). Engwall (2003) argued "no project is an island" and therefore studies need to consider the context of the project. Packendorff and Lindgren (2013, pp. 8) went further to develop a broad view of projects that includes the "individual experiences of project work" as opposed to solely focusing on structure or success. They also called for studies to expand beyond "usual industries, among the usual professionals and through the established channels" (Packendorff \& Lindgren, 2013, pp. 9). Despite these 
advances, the literature has generally remained confined to formal commercial organizing. We point to three areas in the literature relevant to our study: the temporary-permanence relationship, unconventional organizing, and researcher positioning.

The relationship between temporary organizations and permanence has gained traction in recent years (Burke \& Morley, 2016). Engwall (2003, pp. 790) argued for projects as "history-dependent and organizationally-embedded", taking into account the ways in which they connect with other permanent structures. For Sydow and Windeler (2020), all organizations contain some balance of permanent and temporary. These views rest on the ontological assumption that a connection exists between the temporary organization and a permanent organization. While all temporary organizations are enacted within permanent societal and institutional settings, this emphasis on permanent organizations ignores less conventional types of organizing like temporary organizations unattached to permanent organizations. Social protest offers one such example and can respond to calls to explore the impact of temporary organizations on larger institutions.

Temporary organizing appears commonly in social movement literature with "spontaneous protest" as a recognizable feature (Levinson, 2015). While some protests are connected to a permanent organization, such as a miners' strike (Levinson, 2015), others appear as grassroots movements, such as Occupy London (Reinecke, 2018). No protest expects to be permanent, rather they come to an end for one of two reasons. First, as in many projects, the organization pre-plans disbandment based on time or scope. For example, NATC formed specifically to protest a UN climate conference and subsequently dissolved afterward (McCurdy and Uldam, 2014). Second, the organization begins with an indeterminate lifespan then closes due to the success or failure of organizational goals. For example, police evicted 
two Occupy London camps bringing the organization to an end (Reinecke, 2018). Research on social movements, even within organizational studies, commonly fails to examine the temporary nature of the organization.

In terms of researcher positioning, the relationship between temporary organizing and taking sides has rarely been explored explicitly. One reason for this is that many studies of temporary organizations use retrospective case study methods or interviews as opposed to in situ methods where researchers would more commonly face questions of taking sides (Lindgren et al., 2014). Additionally, studies that focus on discursive elements, as opposed to action and experience, situate the researcher as observer more than participant (Engwall, 2003; Packendorff \& Lindgren, 2013; Lindgren et al., 2014). In ethnographic research of formal temporary organizations, as well as permanent organizations, the researcher assumes the role of outsider at the start and over time negotiates a balance between staying an outsider and becoming an insider (Bruskin, 2019). However, the researcher's role in a short-term informal temporary organization like Lyra's Walk differs, with membership defined by action and participation rather than by a formal process of gaining membership.

Lastly, the embodied experience of temporary members becoming within a temporary organization is understudied (Bakker et al., 2016; Tsoukas \& Chia, 2002). Becoming within an organization refers to the ongoing process of actors making sense of their place and taking action (Tsoukas \& Chia, 2002). From the researcher's perspective this concept can be applied to questions of taking sides when participating in a temporary organization. To better examine this question, we will first review perspectives on embodied walking ethnography and how this approach affects a researcher's perspective. 


\section{Researching Protest through Embodied Walking Ethnography}

As an environment with complex spatial realities, Northern Ireland is particularly well suited to an embodied walking methodology that focuses upon sociality, physicality, and emotionality. In this place, the effects of conflict on relationships between people, places and movement can be understood through a mobile methodology that "capture[s] the multidimensional nature of socio-spatial exclusion" (Hocking et al., 2018, pp. 877). By combining embodiment with walking ethnography, we were able to obtain rich data that captures “subjects' stream of experiences and practices as they move through, and interact with, their physical and social environment” (Kusenbach, 2003, pp. 463). This approach incorporates researcher reflexivity. By positioning ourselves as participants alongside other walkers, we were able to collect rich data not otherwise available to those who did not experience the physical and emotional journey of walking with others. To position ourselves within the literature we discuss walking, embodiment, reflexivity and emotion as research methodologies for studying temporary organizations.

Since the temporary organization we studied took place in motion, walking served as a fundamental part of the organization and therefore of our research approach. Moving with others is an inherently social act, creating feelings of closeness between the participants, environment and researcher. Engaging with the sociality of walking serves as a research technique where the researcher connects with participants through shared experiences. Combining sociality with the physicality of endurance walking deepens the researcher's engagement with participants (Kusenbach, 2003; Lee \& Ingold, 2006; Pink, 2008). By walking with others, the researcher becomes a part of the organization and of participants' lives, giving them meaningful access to participant perspectives, sensations and emotions. This creates rich data that goes beyond the structure of the organization, the route travelled, 
and the discourse of participants, to understand the multifaceted experiences of walking and feeling together.

When utilized as an embodied type of ethnography, walking with others involves an awareness of and emphasis upon participant and researcher senses that goes beyond what can be obtained during interviews or participant observation (Lee \& Ingold, 2006; Pink, 2008). Lee and Ingold (2006, pp. 67) explain that "walking does not, in and of itself, yield an experience of embodiment, nor is it necessarily a technique of participation. Rather, both embodiment and participation presuppose some kind of attunement, such that both the ethnographer's pedestrian movements and those of the people she or he is with are grounded in shared circumstances." Within the context of walking, embodiment refers to the ways in which the body engages with and reacts to the environment through which it moves. The body connects with the surrounding environment, sensing temperature, weather, inclines and declines, walking surfaces, proximity to other walkers and cars, and other aspects of the landscape (Lee \& Ingold, 2006; Pink, 2008). The environment imprints upon the body through the skin (e.g. sensations of cold or wet), the limbs (e.g. perceptions of the landscape felt in feet and legs), the muscles and skeleton (e.g. through aches and bodily transformations like blisters or other injuries).

Epistemologically, the emotions of ethnographic research in a conflict setting also have a significant impact upon the research as "the emotions evoked, experienced, and shaped in the field largely influence the way we as researchers act in the field" (Diphoorn, 2013, pp.202). Although rarely addressed in organizational research, emotions cannot be separated from the research as they are embodied by the researcher and therefore affect data collection, interpretation and presentation (Diphoorn, 2013; Mazzetti, 2016; Mikkelsen, 2013). As Whiteman (2010) explains, management studies benefit from engaging with the deep 
emotions that arise through shared experiences with the people we study and the data we collect. She identifies two potential benefits to discussing strong emotion in management studies: first, by treating emotions as analytic clues we deepen our understanding of the phenomena we study, and second this approach allows us to more deeply and authentically represent the lives of the people we study (ibid., pp. 335). As Lyra's Walk was a deeply emotional journey for participants, an analysis of this organization must engage with the emotions of both participants and researchers.

Using an embodied approach also requires researcher reflexivity to make sense of his/her own sensations and emotions, and to understand how they influence the data and analysis. This requires critical reflection on the researcher's role in the research (Mikkelsen, 2013; Tallberg et al., 2014). Through this reflexive process, we identified that that act of "walking with" others equated to taking the side of the temporary organization, Lyra's Walk. As full participants, we both affected and were affected by the other participants who composed the organization. In this way we utilized what Gherardi (2019) calls an "affective ethnography" style, engaging in embodied ways of knowing, being with and becoming with other walkers. This affective ethnographic process "relies on the researcher's bodily capacity to affect and be affected and to focus on the intra-action between the production of data by the researcher and how data produce the researcher" (ibid., pp. 14). Consequently, by taking sides, we gained deep insights into the experience of walking with others as part of a temporary protest organization and the meaning ascribed to these experiences (see also Lubit, 2020).

This approach differs from other methodologies where the question of taking sides arises. Other qualitative research methods require researchers to take sides, either for or against their participants. For example, participatory action research and militant ethnography generate coconstructed accounts between researcher and participants. Participatory action research gives 
voice to the "often overlooked in a society" with a particular focus on practical solutions for participants (Dover \& Lawrence, pp. 307), while militant ethnography involves the "vigorous pursuit of, and dissemination of, partisan insights" (Apoifis, 2017, pp. 13). Both methodologies consist of research for and with participants. In contrast, other methodologies place the researcher in opposition to and against participants. Taking inspiration from ethnomethodological breaches, researcher-initiated disruption pits the researcher temporarily against participants (Gidley, 2020). Going one step further, researchers doing covert research into antagonistic organizations sublimate their own perspective in order to study an organization with oppositional values (Maguire et al., 2019). While each of these examples tends to take one position for or against participants, an embodied walking ethnography takes a less fixed position. Our approach aligns with that of McCurdy and Uldam (2014, pp. 52) who identified that a continuum of positioning exists during participant observation of social movement organizations, and that positioning can change throughout the course of an ethnography.

\section{Methodology}

Paradigmatically situated within an interpretive epistemology influenced by anthropology (first author) and organizational studies (second author), we agreed that ethnography was the most appropriate methodology to explore the lived experiences of the walkers. Organizational ethnographies of temporary organizations are rare (an exception - van Marrewijk et al., 2016) due to the temporary nature of the organizations (Bakker et al., 2016); yet, the structured ephemeralness (Raulet-Croset \& Borzeix, 2014) and planned moment of Lyra's Walk drew us to study the phenomenon from an organizational perspective. Engaging in the walk as participants defined us as members of the temporary organization, as "insiders" (Bruskin, 2019). We chose to focus on the temporal present, forswearing retrospective interviews in favor of the in situ experience of becoming (Hamilton \& Taylor, 2013).The past and future 
provided context only in how they helped to explain how temporary organizations are "constituted in lived time" by their members (Lazar, 2014).

\section{Data collection}

In order to ensure a multidimensional understanding of the organization from the perspectives of organizers, participants and outsiders, we used a combination of data collection approaches. This included embodied walking ethnography through participation as walkers; unstructured interviews; visual methods of photography and video throughout the walk; online ethnography to collect data posted on social media and blogs by organizers, participants, and observers before, during and after the walk; and a review of media reporting on the event. Having both researchers participate in data collection at the event increased the robustness of our data set.

Both authors participated in the first and third days of the walk, walking 28 miles and 18 hours alongside participants. We collected field notes throughout, recording our observations along with data on our social, physical, and emotional experiences of the walk. The walk was physically exhausting and imprinted itself on our bodies through blisters and sore muscles. We experienced numerous hazards and hardships including the physical toll of the walk on our bodies; a seemingly endless thirst and hunger; and extreme weather in the form of rain, wind and hail. The difficulties associated with this type of walking helped to make Lyra's Walk a highly emotional experience for all participants, many who like us were not trained in endurance walking. Recognizing the significance of these experiences, we collected data from participants and ourselves on the body, emotions, and various other senses (e.g. sounds, sights, smells, tastes) engaged throughout the event. 
We also conducted interviews with 25 individuals; each researcher interviewed 15 participants, with five individuals being interviewed by both. Interviews ranged from 15 to 90 minutes in length and were conducted while walking and during rest breaks. We made initial contact with most interview participants on day one, identifying ourselves as researchers and asking questions about who they were, why they attended, their expectations, emotions associated with participation, and their experiences of the walk to that point. We also engaged in follow-up conversations on day three along with interviews with a few additional walkers, but the length and depth of most conversations were limited on day three due to exhaustion and the hardship of walking conditions. We gathered information on participants' perceptions of their role as walkers, their emotions and physical experience of walking, changes between the beginning and end of the walk, and the significance of the protest.

We collected data in classic ethnographic fashion by recording field notes and the content of walking interviews in real time or shortly after an interaction (Pink, 2008; Raulet-Croset \& Borzeix, 2014). The use of field notes in walking ethnography is particularly important due to the "often fleeting and ineffable" moments that occur when moving through time and space (Yi'En, 2014). To capture these moments, we typed notes and recorded voice memos on our smartphones both while walking and during rest breaks. Participants were comfortable with notetaking while conversing, so we were able to obtain accurate "thick" descriptions (Geertz, 1973). At the end of each day, we reviewed and expanded upon our notes, developing them into 'field stories' (Van Maanen, 1988). We complemented written notes with 165 photos and 10 short videos taken throughout the walk. This visual data acted as a tool for reengaging with the sights, sounds and emotions of the walk afterwards and could be utilized to complement written text. Lastly, we used data collected from social media, blogs and media reporting to provide context for the walk and to serve as points of comparison to participants' verbalized motivations and experiences. 


\section{Data Analysis}

Our data analysis began with two paradigmatic assumptions. First, we sought to reach an embodied emic view of the organization, which included our own perspectives alongside those of other members. As such, "the record of the walk, and of the experience it affords, is just as important - and just as valid a source of field material - as the record of the 'discourse' that might have accompanied it”' (Lee \& Ingold, 2016, pp. 83). Second, the analysis required context beyond temporary organizational timescale (Engwall, 2003). While our primary focus remained upon the period of time during the event, we also considered both the before and after periods in order to provide further contextualization.

We applied a 'narrative strategy' to data analysis (Langley, 1999). First, we read through our field stories to identify events that involved taking sides or making choices related to our position in the organization. Since we participated as full members of the organization, we took our own perspectives, sensations and emotions into consideration as well, comparing them to those expressed by other members. Once we identified a side-taking event, we considered the context - the choices, circumstances, and roles of other organizational members - for additional perspective. We then took a holistic approach to our data, considering how these individual events provided insight into the organization and the narrative of Lyra's Walk. These analyses were conducted both alone and in discussion between the two authors. As a final step, we examined how our choice of methodology influenced our ethnography and what it meant for the analysis and the organization. Through this lens, we consider our insights into our methodology as findings and will discuss that in greater detail in the following section. 


\section{Becoming a Part of Lyra's Walk}

As revealed in organizational ethnography studies, organizations are often more complicated and messier on the inside than they appear from the outside (Luthans et al., 2013). The same held true of Lyra's Walk. As human beings we could not remain objective and separate our emotions from our research. As Mazzetti (2016, pp. 312) demonstrated, these types of personal connections make ethnographic researchers "better able to connect with [their] participants which ultimately [leads] to new insights and understandings." At the same time, these connections make ethnographic research more complex, requiring a certain level of self-awareness and a willingness to continuously negotiate our roles.

As most members of a temporary protest organization enter as strangers (Meyerson et al., 1996), they must negotiate their place and role upon entry. The same was true of participation in Lyra's Walk which required us to confront our position in relation to other protesters and in relation to Northern Ireland's sectarian conflict. This required reflexivity about tensions we experienced, different aspects of our identities, and ways our identities were expressed at different times throughout the protest. During the walk we found ourselves at different positions on a spectrum between the extremes of feeling like an outsider/researcher or insider/walker. This compares to the continuum proposed by McCurdy and Uldam (2014). Through conversations with other walkers we identified that others engaged in the same process of negotiation and positioning.

Lyra's Walk did not fully come into being as an organization until the action of walking began. Additionally, unlike other types of temporary organizations, it had no connection to a permanent organization, contributing to feelings of uncertainty for members. Becoming a member of the organization occurred not by organizing or registering for the walk, but by walking, regardless of the time and distance completed. As described by Tsoukas and Chia 
(2002) becoming is a continuous process of action and change. In the following stories, we illustrate this process through discussions of how participants began by feeling they did not belong; yet through the social, physical and emotional journey of walking they became a part of Lyra's Walk.

Figure 2. Small groups waiting for the walk to start in Belfast, day 1. Photo by first author.

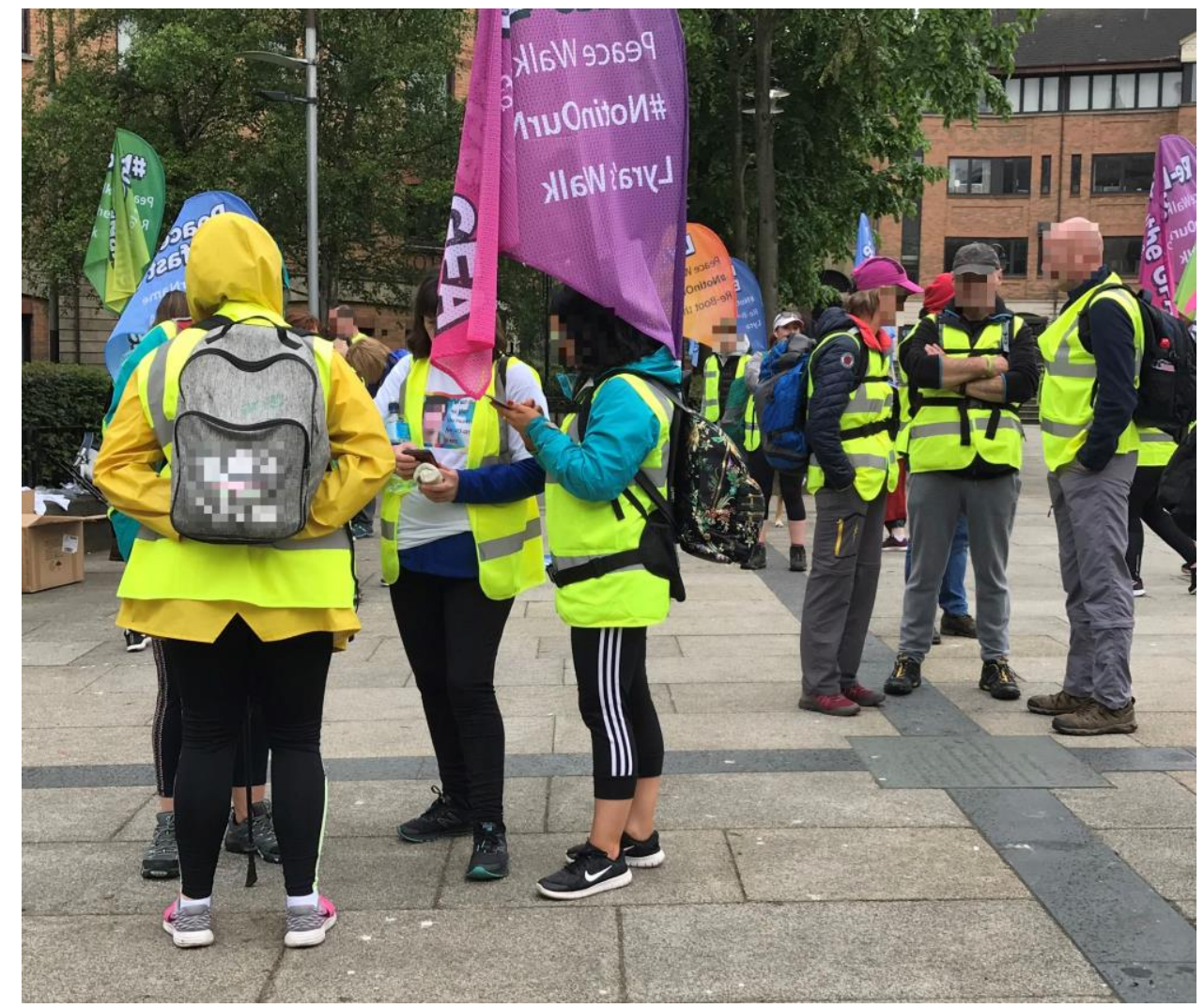

Travelling together, the authors arrived at Writer's Square in central Belfast at 8:30 am on a Saturday in May, the first day of the walk. Over the next thirty minutes other participants, local organizations supporting the walkers, and the media arrived to fill the square. Everyone stood separately in small groups of friends and family, waiting for organizers to signal the start (see figure 2). Not knowing anyone else, we self-consciously stood on our own, feeling isolated and like we did not truly belong. We began speaking to other walkers over the first few miles and noticed that they echoed similar feelings of not fully belonging. Most 
commonly, individuals differentiated themselves from what they considered to be full members of the organization by stating that they were neither friends nor family of Lyra. The best example of this was a conversation with two Northern Ireland women in their thirties who walked the first four miles only. When asked why they were walking, they answered "we have no connection to Lyra, but the events connected with her death have touched a lot of people." Once they made their position as outsiders clear, they were reluctant to speak further, believing that because they had no connection to Lyra and were not walking more than a few miles, they were not true representative members of the organization. Many others explained their positions in similar ways, judging their membership in terms of how much they walked and whether or not they had connections to Lyra.

Even those with direct connections to Lyra felt they did not truly belong. We spoke extensively with Peter (pseudonym used) who shared the story of how the walk was conceived by five of his friends, who were close to Lyra, while sitting at a kitchen table one night. Although he was present in this moment and during other preparations made for the walk, he did not consider himself one of the organizers and made a point of differentiating himself, referring to "them" as opposed to "us". This demonstrates how walkers felt separate from the organization during the first miles of the first day, not yet knowing each other or their roles. This changed gradually as walkers engaged with the intense physical experience of participation.

The further we walked together, the more we developed a sense of camaraderie through shared experience (see figure 3). This first occurred as we approached a rest stop four miles from the starting point. Our police escort had unexpectedly left us at the Belfast city limits, right as we approached a long steep uphill section of road with no sidewalks. Acknowledging the very real hazards, the stewards explained conditions to the crowd while follow-cars 
stopped to give walkers the opportunity to ride or to lighten their loads. Although there was little conversation due to the intensity of the uphill climb, this was when solidarity between walkers and those supporting us first appeared. We walked in tight proximity and protected each other through this shared physical struggle. Upon reaching the rest stop, walkers began to get to know each other, engaging in conversation, sharing food, and handing out plastic ponchos since it had begun to rain. The group was drawn together by shared anger at being abandoned by our police escort and by feelings of accomplishment for having managed the hazards through cooperation. This served as a significant event in the process of becoming Lyra's Walk. The organization was no longer an intangible concept. Our actions and choices had shaped the development of its identity.

Figure 3. Participants walking and talking close together, day 3. Photo by first author.

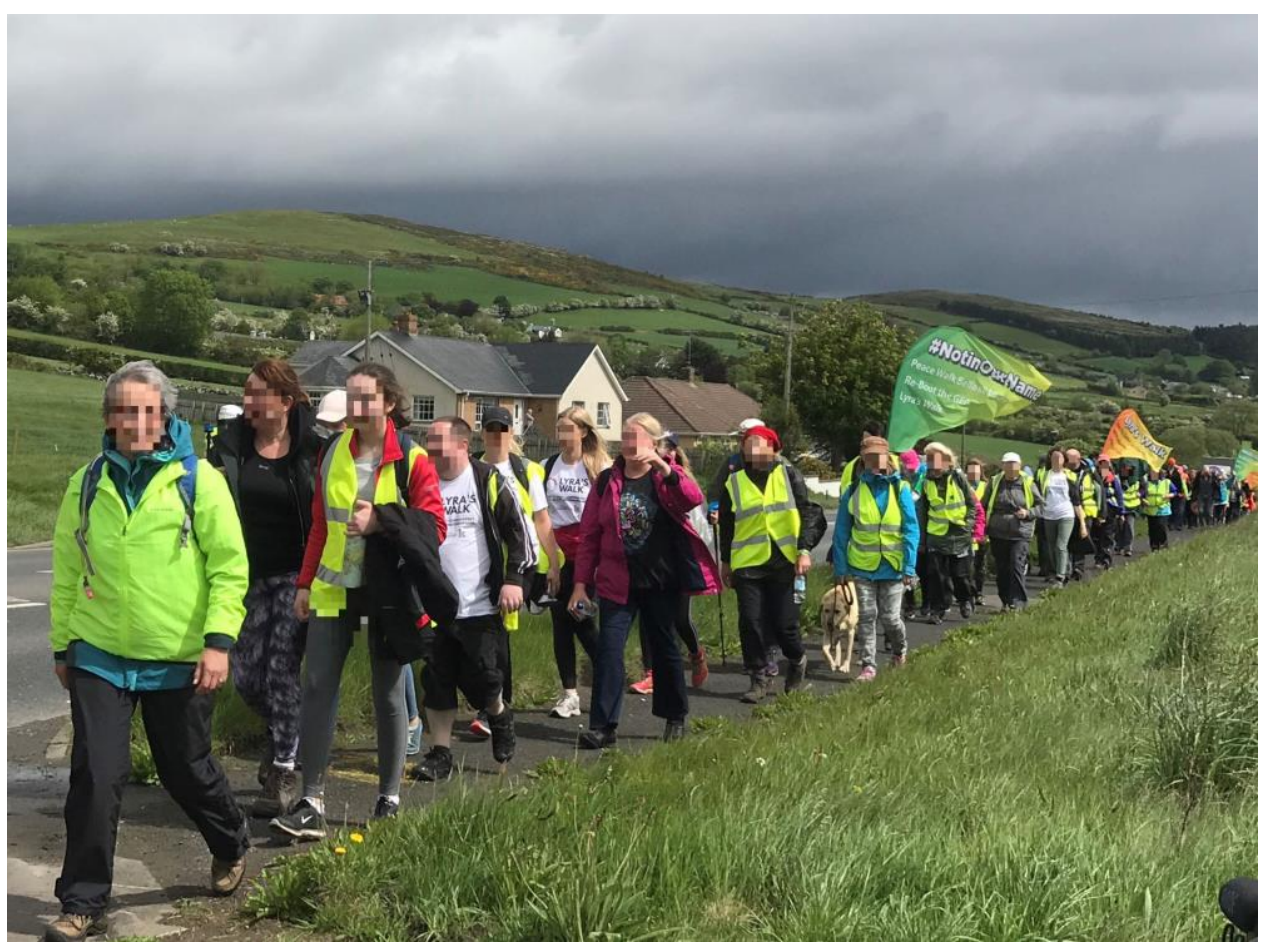

Ahead of time, the organizers encouraged anyone not wishing to complete the entire day's walk to leave here and return to Belfast. To continue meant committing to an additional 11 miles minimum, as we would walk through the countryside with no public transportation 
available. Although the authors originally planned to leave the walk here, we had begun to feel emotionally invested and connected with the other walkers. Not wanting to lose this feeling, we continued onward to complete sixteen of the twenty miles the group walked that day. Our feelings of uncertainty and lack of place seemed to dissipate the further we went and the more we experienced together as a collective.

The farther we walked the more the physicality of the walk impacted us. At a rest stop nine miles from the start, all walkers filed into a church to use the bathrooms, eat, drink, rest and receive first aid if needed. The first author captured the moment in field notes:

They told everyone we had to keep going because if we stopped for too long it would be difficult to get going again. I have to agree with this, as at this point, I felt a strong tug of longing to sit in a chair and rest my feet which had developed several blisters. After leaving the church, everyone was much more subdued, myself included, as we'd walked nine miles (but over 10 more miles to go). About 15 minutes later I couldn't keep going and stopped to put plasters on my toes as a few people passed me.

Stopping walking at the rest stop allowed walkers to become aware of the ways in which the walk imprinted itself upon our bodies. Shoes were removed, muscles massaged, knees bandaged, and medics were kept busy moving from person to person. As the physical impact of the walk made itself felt, the sociality experienced in the earlier stages took on a new form. The walkers had become subdued with fewer conversations taking place. Now we connected to one another not through verbal communication but through a shared physical struggle.

Over time and distance, we shared in the physicality of walking together over long distances, on challenging roads, in the cold and rain, with blisters and sore muscles.

This brings us to a discussion of the emotionality of participation through walking, which cannot be fully separated from the social and physical aspects. Although emotional aspects were visible throughout, our experience on the third and final day best demonstrated the emotions that accompanied participation. After nine miles walked that morning in the wind, 
hail, cold and pouring rain, we arrived at the final resting point prior to walking the final three miles into the city of Derry/Londonderry. The first author documented her thoughts and feelings in that moment:

By the time we approached the YMCA, I was soaking wet and cold, feeling pretty miserable and tired. I didn't even see the group standing there initially. But when I heard them, and realized they were standing there for us / for me, I felt a wave of emotions rise within me. We came face to face with a mass of supporters welcoming us with chants and claps. It was overwhelming to transition out of the harsh weather into an enclosed hallway space, with both sides lined by people supporting us. I felt overwhelmed with emotion - my eyes tingling and tears welling up in response to a feeling of support and love.

As we entered the YMCA our embodied emotions told us that we were full members of the organization. We had experienced joy, hope, pain, hunger, exhaustion and harsh weather together with other walkers throughout our journey. The reception by those greeting us helped to highlight those elements that made the walkers a collective and cohesive group under the name of Lyra's Walk. The contrast between "us" and "them" brought about an awareness of what we had experienced together and of the strong emotional bonds we had formed with one another and with Lyra's Walk.

Each member of the protest had their own motivations for participating, with diverse backgrounds, experiences, and concerns. They came together through a shared interest in the walk's ideology. Through the act of walking they became a cohesive whole, first connecting through conversation and cooperation, and then through a shared journey which created a communal sense of purpose and perseverance. They became full members not only through their bodily presence as protesters but through solidarity and a shared intensive physicality that inspired the growth of emotional connections, friendships, and a common identity. Russo (2014, pp. 67-68) demonstrated a similar phenomenon in her ethnography of the annual 75mile Migrant Trail march, describing the event as "a deeply emotion-laden, physically demanding engagement...[that] offers allies the embodied and emotional resources necessary 
to forge collective identity." Through "compassion, commitment, and physical vulnerability in close proximity to others" participants bond strongly. (ibid., pp. 69) As one participant stated in the final stages of Lyra's Walk, "we are all family now." Regardless of differences participants identified between one another at the start of the walk, through shared experiences they felt drawn into feelings of solidarity.

By utilizing embodied walking ethnography, we were able to experience the same physical challenges, sensory perceptions, and strong emotional bonds as other walkers. Through our bodies we experienced the walk and what it meant to participate. The embodied experience of walking as a protester led to a continual engagement with a range of emotions and questions about our simultaneous roles as protesters and researchers. By participating in and lending our bodies to the protest, we became allies in the social movement (Russo 2014). This type of "participation obliges us to experience emotions - and when understanding them, reflecting on them, and analyzing them, we acquire a more enriched grasp of the research setting" (Diphoorn, 2013, pp. 220). Therefore, the emotionality of experiencing with others allows for otherwise inaccessible insights. In the case of Lyra's Walk, these insights would not have been accessible without engaging in a walking methodology, since walking was fundamental to participation and belonging.

\section{Concluding Remarks on Taking Sides}

We sought to answer the question of how embodied walking ethnography impacts the study of protest organizations. We used Lyra's Walk as an example of how this approach allows the researcher to become intertwined with the organization and its members during the process of organizational becoming. We concluded that social, physical and emotional aspects of walking facilitate this process and generate further insights into the study of protest. 
In answer to our question, we identified that our methodological choice had a significant impact upon the ways in which we took sides during our research. We reflect on taking sides from three perspectives: the sectarian conflict in Northern Ireland, the temporary organization, and the methodology. From a conflict perspective, participation through embodied walking ethnography meant aligning ourselves with the ideology and goals of the protest, in opposition to sectarian political parties and paramilitaries of Northern Ireland. From the temporary organization's perspective as well, we took the side of other walkers and of their lived experiences throughout the protest. Taking sides here meant sharing in the same social, physical and emotional experiences as other people walking alongside us. The methodology of embodied walking ethnography made these experiences accessible to us.

Due to the nature of the protest, membership in Lyra's Walk was defined by the act of walking alongside others on a planned route. From an external perspective, the act of walking with our research participants made us as much members of the organization as any other participant, in contrast to more common applications of ethnography where the ethnographer is temporarily accepted into the culture (Geertz, 1973) or organization (Van Maneen, 1988). By choosing to "walk with" others (Lee \& Ingold, 2006), we became part of the temporary protest organization and shared in the experiences of other protestors. More importantly, the choice to engage in Lyra's Walk as full participants meant we shared in the same emotional and physical journey as other participants. We experienced camaraderie, physical hardship and intense emotions alongside one another. Therefore, the walking aspect of our participation was crucial to our becoming part of the organization and to being able to collect deep ethnographic data on what participation meant throughout the life of the organization.

In addition to the methodological contribution, our research suggests a possible relationship between temporariness and permanence. Although a researcher's work in a permanent 
organization remains temporary, in a temporary organization a researcher's presence can become permanent. When participating in the becoming and unbecoming of the whole organization, as we did with Lyra's Walk, the researcher acts as a member throughout the lifespan of the organization, making their presence permanent. Through the act of walking, our bodies combined with those of other members to construct the protest, meaning that our presence left its imprint upon the organization at the same time as the organization imprinted itself upon our bodies. Returning to Engwall's (2003) metaphor, we acknowledge the connection between Lyra's Walk, other permanent organizations and the institutional context. Although connected, Lyra's Walk was neither an extension of nor accountable to them. We saw this most visibly through the interaction between the walkers and the police; as we described, the group continued walking onward despite the loss of a police escort and the resulting risk to personal safety, instead depending upon one another to successfully climb the treacherous hill.

Finally, we identified several practical implications of this research in relation to social protest, temporary organizations, transferability, and embodied walking ethnography. First, we demonstrated some of the complexity involved in social protest organizations including the ways in which the body plays a part in constructing belonging. This can have practical implications both for researchers seeking to research protest organizations and for organizations seeking to better understand how to bring its membership together as a cohesive whole. Second, we have investigated an unconventional form of organizing where action rather than discourse was the defining feature of membership. As noted by Sydow and Windeler (2020), less conventional organizations have an increasing impact upon broader society and deserve further attention. Third, our findings are transferable to several settings including other informal protest organizations and socio-political movements, such as Black Lives Matter (Milkman, 2017), and organizations or parts of organizations defined by 
physical movement, such as sport. Future research could explore the balance between social, emotional, and physical aspects across different settings. Finally, we called attention to the methodological and practical consequences of using an embodied walking ethnography. This approach requires the researcher to use their body to engage physically and emotionally, which can be an uncomfortable and unfamiliar way of researching. Additionally, it requires researchers to engage in reflexivity, to consider the ways in which the resulting connections with other participants influences their data and interpretations. 


\section{References}

@lyraswalk (2019a, April 25), “Are you up for the challenge?”, Retrieved 22 May 2019, from https://www.facebook.com/lyraswalk/ (page has been deleted).

@lyraswalk (2019b, May 10), “Launch of Lyra’s Walk charter”, Retrieved 22 May 2019, from https://www.facebook.com/lyraswalk/ (page has been deleted).

Apoifis, N. (2017), "Fieldwork in a furnace: anarchists, anti-authoritarians and militant ethnography", Qualitative Research, Vol. 17 No. 1, pp. 3-19.

Bakker, R. M. (2010), "Taking stock of temporary organizational forms: A Systematic Review and Research Agenda", International Journal of Management Reviews, Vol. 12 No. 4, pp. 466-486.

Bakker, R. M., DeFillippi, R. J., Schwab, A., \& Sydow, J. (2016), “Temporary organizing: Promises, processes, problems", Organization Studies, Vol. 37 No. 12, pp. 1703-1719.

Becker, H.S. (1967), “Whose side are we on?”, Social Problems, Vol. 14 No. 3, pp 239-247.

Bruskin, S. (2019), "Insider or outsider? Exploring the fluidity of the roles through social identity theory", Journal of Organizational Ethnography, Vol. 8 No. 2, pp. 159-170.

Bryan, D. (2017), "From civil rights to carnival: The anthropology of public space in Belfast", In D. O Giolláin (Ed.), Irish Ethnologies (pp. 126-130), University of Notre Dame Press, Notre Dame.

Burke, C.M. \& Morley, M.J. (2016), "On temporary organizations: A review, synthesis and research agenda", Human Relations, Vol. 69 No. 6, pp. 1235-1258.

Diphoorn, T. (2013), "The emotionality of participation: Various modes of participation in ethnographic fieldwork on private policing in Durban, South Africa", Journal of Contemporary Ethnography, Vol. 42 No. 2, pp. 201-225.

Dover, G., \& Lawrence, T. B. (2010), “A gap year for institutional theory: Integrating the study of institutional work and participatory action research, Journal of Management Inquiry, Vol. 19 No. 4, pp. 305-316.

Engwall, M. (2003), "No project is an island: Linking projects to history and context", Research Policy, Vol. 32 No. 5, pp. 789-808.

Geertz, C. (1973), The interpretation of cultures: Selected essays. Basic Books, New York, NY.

Gherardi, S. (2019), "Theorizing affective ethnography for organization studies", Organization, Vol. 26 No. 6, 741-760.

Gidley, D. (2020), "Creating institutional disruption: an alternative method to study institutions", Journal of Organizational Change Management, Vol. ahead-of-print No. aheadof-print. https://doi.org/10.1108/JOCM-06-2019-0200.

Graham, B. \& Nash, C. (2006), “A shared future: Territoriality, pluralism and public policy in Northern Ireland", Political Geography, Vol. 25, pp. 253-278.

Hamilton, L. and Taylor, N. (2012), "Ethnography in evolution: adapting to the animal 'other' in organizations", Journal of Organizational Ethnography, Vol. 1 No. 1, pp. 43-51. 
Hocking, B.T., Sturgeon, B., Whyatt, D., Davies, G., Huck, J., Dixon, J., Jarman, N. \& Bryan, D. (2018), "Negotiating the ground: 'Mobilizing' a divided field site in the 'postconflict' city”, Mobilities, Vol. 13 No. 6, pp. 876-893.

Jacobsson, M. \& Hällgren, M. (2016), "Impromptu teams in a temporary organization: On their nature and role", International Journal of Project Management, Vol. 34 No. 4, pp. 584596.

Jarman, N. \& Bell, J. (2012), "Routine divisions: Segregation and daily life in Northern Ireland", In C. McGrattan \& E. Meehan (Eds.), Everyday life after the Irish conflict: The impact of devolution and cross-border coorperation (pp. 39-53), Manchester University Press, Manchester.

Kusenbach, M. (2003), "Street phenomenology: The go-along as ethnographic research tool", Ethnography, Vol. 4 No. 3, pp. 455-485.

Langley, A. (1999), "Strategies for theorizing from process data", The Academy of Management Review, Vol. 24 No. 4, pp. 691-710.

Lazar, S. (2014), "Historical narrative, mundane political time, and revolutionary moments: Coexisting temporalities in the lived experience of social movements", Journal of the Royal Anthropological Institute, Vol. 20, pp. 91-108.

Lee, J. \& Ingold, T. (2006), "Fieldwork on foot: Perceiving, routing, socializing", In S. Coleman \& P. Collins (Eds.), Locating the field: Space, place and context in anthropology (pp. 67-86), Berg, Oxford.

Levinson, A. (2015), "Protest and self-organization", Sociological Research, Vol. 54 No. 4, pp. 248-273.

Lindgren, M., Packendorff, J., \& Sergi, V. (2014), "Thrilled by the discourse, suffering through the experience: Emotions in project-based work", Human Relations, Vol 67 No. 11, pp. 1383-1412.

Lubit, A. J. (2020), "Walking together as protest: collective identity transformation in sectarian Northern Ireland", Anthropological Notebooks, Vol. 26 No. 1, pp. 12-32.

Lundin, R.A. and Soderholm, A. (1995), "A Theory of the temporary organization", Scandinavian Journal of Management, Vol. 11 No. 4, pp. 437-455.

Luthans, F., Milosevic, I., Bechky, B. A., Schein, E. H., Wright, S., John, V. M., \& Greenwood, D. J. (2013). "Reclaiming 'anthropology: The forgotten behavioral science in management history' - commentaries”, Journal of Organizational Ethnography, Vol 2 No. 1, pp. 92-116.

Maguire, H, McCartan, A, Nash, CJ, Browne, K. (2019), "The enduring field: Exploring researcher emotions in covert research with antagonistic organisations", Area, Vol. 51 No. 2, pp. 299- 306.

Mazzetti, A.S. (2016), "An exploration of the emotional impact of organisational ethnography”, Journal of Organizational Ethnography, Vol. 5 No. 3, pp. 304-316.

McCurdy, P., \& Uldam, J. (2014), "Connecting participant observation positions: Toward a reflexive framework for studying social movements”, Field Methods, Vol. 26 No. 1, pp. 4055. 
Meyerson, D., Weick, K.E. and Kramer, R.M. (1996). "Swift trust and temporary groups.” In Kramer, R.M. and Tyler, T.R. (Eds.), Trust in Organizations: Frontiers of Theory and Research (pp. 166-195), Sage, Thousand Oaks, CA.

Mikkelsen, E. N. (2013), “A researcher's tale: How doing conflict research shapes research about conflict", Qualitative Research in Organizations and Management, Vol. 8 No. 1, pp. 33-49.

Milkman, R. (2017), “A new political generation: Millennials and the post-2008 wave of protest”, American Sociological Review, Vol. 82 No. 1, pp. 1-31.

Murphy, J. (2015), "Tracking change in Northern Ireland policing: Temporal phases and key themes", Policing: And International Journal of Police Strategies and Management, Vol. 38 No. 1, pp. 117-131.

O’Neill, J. (2019, April 19), "Lyra McKee murder: Journalist shot dead during Derry rioting," $B B C$ News, Retrieved from https://www.bbc.com/news/uk-northern-ireland47985469.

Packendorff, J \& Lindgren, M. (2014), "Projectification and its consequences: Narrow and broad conceptualisations", South African Journal of Economic and Management Sciences, Vol. 17 No. 1, pp. 7-21.

Pink, S. (2008), "An urban tour: The sensory sociality of ethnographic place-making", Ethnography, Vol. 9 No. 2, pp. 175-196.

Raulet-Croset, N. and Borzeix, A. (2014), "Researching spatial practices through Commentated Walks: 'on the move' and 'walking with'", Journal of Organizational Ethnography, Vol. 3 No. 1, pp. 27-42.

Reinecke, J. (2018), "Social movements and prefigurative organizing: Confronting entrenched inequalities in Occupy London”, Organization Studies, Vol. 39 No. 9, pp. 1299 1321.

Russo, C. (2014). "Allies forging collective identity: Embodiment and emotions on the Migrant Trail,” Mobilizations: An International Quarterly, Vol. 19 No. 1, pp. 67-82.

Sydow, J. \& Windeler, A. (2020), “Temporary organizing and permanent contexts", Current Sociology, Vol. 68 No. 4, pp. 480-498.

Tallberg, L.C., Jordan, P.J., \& Boyle, M. (2014), “The 'Green Mile': Crystallization ethnography in an emotive context", Journal of Organizational Ethnography, Vol. 3 No. 1, pp. 80-95.

The Guardian (2020), "Northern Ireland assembly reopens three years after collapse", The Guardian, Retrieved from https://www.theguardian.com/politics/2020/jan/11/northernireland-assembly-reopens-three-years-after-collapse.

Tsoukas, H., \& Chia, R. (2002), “On organizational becoming: Rethinking organizational change", Organization Science, Vol. 13 No. 5, pp. 567-582.

Van Maanen, J. (1988). Tales of the field: On writing ethnography, University of Chicago Press, Chicago, IL.

van Marrewijk, A., Ybema, S., Smits, K., Clegg, S. \& Pitsis, T. (2016), "Clash of the Titans: Temporal organizing and collaborative dynamics in the Panama Canal megaproject", Organization Studies, Vol. 37 No. 12, pp. 1745-1769. 
Whiteman, G. (2010), "Management studies that break your heart", Journal of Management Inquiry, Vol. 19 No. 4, pp. 328-337.

Yi'En, C. (2014), "Telling stories of the city: Walking ethnography, affective materialities, and mobile encounters", Space and Culture, Vol. 17 No. 3, pp. 211-223. 